\title{
The application of uncertainty in human gravity measurement
}

\author{
Ge Zhang \\ School of North China Electric Power University, BaoDing 071000, China \\ Corresponding author
}

\begin{abstract}
This article is based on a person's gravity survey, for example, detailed introduction of the gravity acceleration g measurement, the uncertainty in the human gravity measurement can be applied.

KEYWORD: uncertainty; gravity measurement
\end{abstract}

\section{INTRODUCTION}

The purpose of the measurement is to determine the amount of the measured value. The quality of the measurement results is the most important basis for measuring the credibility of the results. Measurement uncertainty is the quantitative characterization of the quality of the measurement results, the availability of the measurement depends largely on the size of the uncertainty. Therefore, the measurement results must be included in the measurement of the measured value and the measurement uncertainty associated with the value is complete and meaningful.

The meaning of uncertainty refers to the degree of uncertainty of the measured value due to the existence of the measurement error. In turn, also indicates the degree of confidence of the result. It is an indicator of the quality of the measurement results.

In reporting the results of the measurement of physical quantity, it is necessary to give the corresponding uncertainty, on the one hand, it is convenient to use it to assess its reliability, on the other hand, it also enhances the comparability between the measurement results.

Measurement uncertainty degree and error is in metrology research the basic proposition, often used by the metrological testing personnel is also one of the most important concepts in. It has a direct relationship with the transfer of accurate and consistent measurement results the level of reliability and the amount of value, measurement uncertainty is characterized by measuring the true value of the quantity value range of evaluation.

For a long time, people have been pursuing the best way to estimate the value of the measurement, and now the evaluation of scientific measurement results have become particularly important.

The measurement of gravity also has a pivotal position in various fields, small to the overload of the elevator, the gravity of the various parts of the aircraft.

\section{UNCERTAINTY IN HUMAN GRAVITY MEASUREMENT}

\subsection{Theory}

Using the simple pendulum principle to measure the Acceleration of gravity of local, then acquire the G.

(1) $\mathrm{G}=\mathrm{mg}$ (2) $\mathrm{T}=2 \pi \sqrt{\frac{\mathrm{g}}{l}} \quad \mathrm{G}=\frac{4 \pi^{2} \mathrm{n}^{2} m(L-d / 2)}{t^{2}}$

Among them, $\mathrm{D}$ is the diameter of the small steel ball (to reduce the air resistance and select the solid steel ball), L the length of the rope to the bottom of the ball; $\mathrm{M}$ for the quality of the measured object (a student), measured with the results of the home body weight: $52.4 \mathrm{Kg}, \mathrm{N}$ is the total vibration times, this experiment selected $n=50, T$ for the completion of the 50 full time of the vibration.

\subsection{The data processing}

Table 1 The result

\begin{tabular}{lllll}
\hline \multirow{2}{*}{ Unit: $\mathrm{mm}$} & $\bar{L}_{\mathrm{i}}$ & $\mathrm{Vi}$ & $\mathrm{Vi}^{2}$ & $\mathrm{Pi}$ \\
\hline \multirow{2}{*}{$\mathrm{L} 1$} & 1004.2666 & 0.0066666 & 0.0000444 & \multirow{2}{*}{3} \\
$\mathrm{~L} 2$ & 6 & 6 & 4 & 5 \\
$\mathrm{~L} 3$ & 1004.24 & -0.02 & 0.04 & 5 \\
& 1004.2714 & 0.0114285 & 0.0001306 & 7 \\
\hline
\end{tabular}




\begin{tabular}{lllll}
\hline unit: $\mathrm{mm}$ & $\overline{\mathrm{d}}_{i}$ & $\mathrm{Vi}$ & $\mathrm{Vi}^{2}$ & $\mathrm{Pi}$ \\
\hline $\mathrm{d} 1$ & 22.22 & -0.0053333 & 0.0000444 & 4 \\
& & 0.0066666 & 0.0000444 & \multirow{2}{*}{5} \\
$\mathrm{~d} 2$ & 22.232 & 6 & 4 & \\
& 22.222857 & -0.0024761 & 0.0000061 & 7 \\
$\mathrm{~d} 3$ & 1 & & & \\
\hline
\end{tabular}

\begin{tabular}{lllll}
\hline unit: $\mathrm{s}$ & $\overline{\mathrm{t}}_{i}$ & $\mathrm{Vi}$ & $\mathrm{Vi}^{2}$ & $\mathrm{Pi}$ \\
\hline $\mathrm{t} 1$ & 99.98 & -0.0486666 & 0.0023684 & 4 \\
& & & 4 & 3 \\
$\mathrm{t} 2$ & 99.994 & -0.0013333 & 0.0000013 & 5 \\
& 99.977142 & & 0.0004756 & 7 \\
t3 & 8 & 0.0218095 & 5 & \\
\hline
\end{tabular}

$\bar{L}=\frac{P_{1} \bar{L}_{1}+P_{2} \bar{L}_{2}+P_{3} \bar{L}_{3}}{P_{1}+P_{2}+P_{3}}=1004.26 \mathrm{~mm}$

$\sigma_{\bar{L}}=\sqrt{\frac{\sum_{i=1}^{3} p_{i} v_{i}^{2}}{(3-1) \sum_{\mathrm{i}=1}^{3} \mathrm{p}_{\mathrm{i}}}}=0.01 \mathrm{~mm}$

$\bar{d}=\frac{P_{1} \bar{d}_{1}+P_{2} \bar{d}_{2}+P_{3} \bar{d}_{3}}{P_{1}+P_{2}+P_{3}}=22.23 \mathrm{~mm}$

$\sigma_{\overline{\mathrm{d}}}=\sqrt{\frac{\sum_{i=1}^{3} p_{i} v_{i}^{2}}{(3-1) \sum_{\mathrm{i}=1}^{3} \mathrm{p}_{\mathrm{i}}}}=0.0036 \mathrm{~mm}$

$\overline{\mathrm{t}}=\frac{P_{1} \overline{\mathrm{t}}_{1}+P_{2} \bar{t}_{2}+P_{3} \overline{\mathrm{t}}_{3}}{P_{1}+P_{2}+P_{3}}=99.96 \mathrm{~s}$

$\sigma_{\overline{\mathrm{t}}}=\sqrt{\frac{\sum_{i=1}^{3} p_{i} v_{i}^{2}}{(3-1) \sum_{\mathrm{i}=1}^{3} \mathrm{p}_{\mathrm{i}}}}=0.0186 \mathrm{~s}$

\subsection{Estimated value of $G$}

$G=\frac{4 \pi^{2} * 50^{2} * 52.4 *(\bar{L}-\overline{\mathrm{d}} / 2)}{\bar{t}^{2}}=514.033 \mathrm{~N}$

\subsection{Uncertainty evaluation}

Table 2 Standard Uncertainty Component

\begin{tabular}{llll}
\hline $\begin{array}{l}\text { Uncertainty } \\
\text { component }\end{array}$ & Source & $\begin{array}{l}\text { Evaluation } \\
\text { category }\end{array}$ & $\begin{array}{l}\text { Instrument } \\
\text { indication er- } \\
\text { ror (positive) }\end{array}$ \\
\hline u1 & $\begin{array}{l}\text { Repeatability of } \\
\text { length L }\end{array}$ & A & \\
u2 & $\begin{array}{l}\text { Repeatability of } \\
\text { small diameter } \\
\text { D }\end{array}$ & A & \\
u3 & $\begin{array}{l}\text { Repeatability of } \\
\text { time t }\end{array}$ & A & \\
\hline
\end{tabular}

\begin{tabular}{|c|c|c|c|}
\hline $\mathrm{u} 4$ & $\begin{array}{l}\text { The indication } \\
\text { error of the } \\
\text { stopwatch }\end{array}$ & B & $0.01 \mathrm{~s}$ \\
\hline u5 & $\begin{array}{l}\text { The indication } \\
\text { error of vernier } \\
\text { caliper }\end{array}$ & B & $0.02 \mathrm{~mm}$ \\
\hline u6 & $\begin{array}{l}\text { The indication } \\
\text { error of vernier } \\
\text { mater }\end{array}$ & B & $0.5 \mathrm{~mm}$ \\
\hline u7 & $\begin{array}{l}\text { Error of indica- } \\
\text { tion of house- } \\
\text { hold weight }\end{array}$ & B & $0.1 \mathrm{Kg}$ \\
\hline
\end{tabular}

Characterization of the measured values of the given value of the dispersion, and the results of the measurement parameters, known as the uncertainty of the measurement. This is the JJF 1998 - 1001 "universal measurement terms and definitions", the latest definition of its. Measurement uncertainty is a parameter that is independent and closely related to the measurement results, indicating the dispersion of the measurement results. In the complete representation of the measurement, the uncertainty of the measurement should be included. The standard deviation of the measurement uncertainty is called standard uncertainty, and the representation of the half width of the confidence level is called the extended uncertainty.

\subsection{Uncertainty synthesis}

The following data are obtained according to the specification.

(1)Repeatability of length L After the weighted calculation of unequal precision measurement

$$
\begin{aligned}
& \sigma_{\bar{L}}=\sqrt{\frac{\sum_{i=1}^{3} p_{i} v_{i}^{2}}{(3-1) \sum_{\mathrm{i}=1}^{3} \mathrm{p}_{\mathrm{i}}}}=0.01 \mathrm{~mm} \\
& \mathrm{u}_{\mathrm{L}}=\sigma_{\bar{L}}=0.01 \mathrm{~mm} \\
& \mathrm{u} 1=\left|\frac{\partial G}{\partial L}\right| u_{L}=0.005 \mathrm{~N}
\end{aligned}
$$

Its degree of freedom $V_{1}=15-3=12 \mathrm{u} 2$, u3is the same as $\mathrm{u} 1$

(2)The indication error of the stopwatch

Obtained by the instrument manual error range of the stopwatch is \pm 0.01s, Uniform distribution,

$$
\begin{aligned}
& \mathrm{u}_{\mathrm{s}}=\frac{0.01 S}{\sqrt{3}}=0.0058 \mathrm{~S} \\
& \mathrm{u}_{4}=\left|\frac{\partial G}{\partial \mathrm{t}}\right|_{u_{S}}=0.0149 N
\end{aligned}
$$

Relative standard deviation $\frac{\sigma_{\mathrm{u}_{4}}}{\mathrm{u}_{4}}=35 \%$, Its degree of freedom $V_{4}=\frac{1}{2 *(0.35)^{2}}=4$ 
$\mathrm{u} 5, \mathrm{u} 6, \mathrm{u} 7 \mathrm{is}$ the same as u4

Table 3 The result

\begin{tabular}{llll} 
Uncertainty component & & Degrees of freedom & $\mathrm{Vi}^{2}$ \\
\hline u1 & 0.005 & $\mathrm{~V} 1$ & 12 \\
u2 & 0.000 & $\mathrm{~V} 2$ & 12 \\
& 9 & & \\
u3 & 0.191 & $\mathrm{~V} 3$ & 12 \\
& 1 & & 4 \\
u4 & 0.014 & $\mathrm{~V} 4$ & \\
& 9 & & 4 \\
u5 & 0.005 & $\mathrm{~V} 5$ & 4 \\
u6 & 2 & & 4 \\
u7 & 0.149 & $\mathrm{~V} 6$ & 4 \\
\hline
\end{tabular}

The components of the uncertainty are independent of each other. $\rho_{\mathrm{ij}}=0$ Synthetic uncertainty

$\mathrm{u}_{\mathrm{c}}=\sqrt{\mathrm{u}_{1}{ }^{2}+\mathrm{u}_{2}{ }^{2}+\mathrm{u}_{3}{ }^{2}+\mathrm{u}_{4}{ }^{2}+\mathrm{u}_{5}{ }^{2}+\mathrm{u}_{6}{ }^{2}+\mathrm{u}_{7}{ }^{2}}=0.616 \mathrm{~N}$

Degrees of freedom $\mathrm{V}=\frac{\mathrm{u}_{\mathrm{c}}{ }^{4}}{\sum_{i=1}^{7} \frac{u_{i}{ }^{4}}{v_{i}}}=5.56, \mathrm{v}=6$.

\subsection{Extended uncertainty.}

Extended uncertainty is the half width of the range that is measured. That is to say, the extended uncertainty is to determine the amount of the measuring result interval, which is reasonable to give the majority of the measured value distribution is expected to be included in this range. The extended uncertainty is sometimes referred to as the extended uncertainty or range uncertainty, or the total uncertainty. Expanded uncertainty is divided into two types of $U$ and Up. When the measurement results are given, it is generally reported that the extended uncertainty $\mathrm{U}$.

Take the confidence probability $p=0.95$, degrees of freedom $\mathrm{V}=6$, check the $\mathrm{t}$ distribution table, that Coverage Factor $\mathrm{K}=2.45$.

The students' weight of the extended uncertainty.

$\mathrm{U}=\mathrm{Ku}_{\mathrm{c}}=2.45^{*} 0.616=1.509 \mathrm{~N}$

\section{SUMMARY}

The uncertainty of the student's gravity is evaluated by the synthetic standard. $\mathrm{G}=514.033 \mathrm{~N}, \mathrm{u}_{\mathrm{c}}=0.616$, $\mathrm{V}=5.56$. The uncertainty of the student's gravity is evaluated by the Stretch standard $\mathrm{G}=(514.033 \pm 1.509) \mathrm{N}, \mathrm{P}=0.95, \mathrm{~V}=6$

The numerical value of the symbol is $\mathrm{U}=\mathrm{K}=1.509 \mathrm{~N}$, which is determined by the synthetic standard uncertainty and the coverage factor $\mathrm{K}=2.45$.

The uncertainty report is based on the gravity measurement of a single student. The purpose is to master the calculation method of the uncertainty. Understand the difference between error and uncertainty. If this method can be applied to the setting of each instrument, the conclusion will be more accurate. Standard uncertainty is a very important part of the measurement. This paper is to apply the calculation method of uncertainty to the measurement of gravity. In fact, it is very important to calculate the degree of uncertainty in every aspect of life.

The application of measurement uncertainty evaluation is very wide. For different occasions and different requirements, the principle and procedure of the measurement uncertainty assessment is the same, but there will be a slight difference in the specific details. Only by mastering the method of uncertainty evaluation can we solve all kinds of problems in real life.

Contact with real life: A hot air balloon: self weight $6000 \mathrm{~N}$, can load 6900N.At this time, if you want to know the gravity of this student, according to $(514.033+1.509) \mathrm{N}$ calculation. Of course, in practical applications will consider various aspects of the factors. In short, the uncertainty of measurement and our lives are closely linked, only a deeper understanding, you will be able to find the fun.

\section{ACKNOWLEDGMENTS}

The writing of this paper is challenging. I want to take this chance to thanks to my teacher----Mr. Ming. In the process of composing this paper, he gives me many academic and constructive advices, and helps me to correct my paper. Last but not least, I'd like to thank all my friends, especially my five lovely roommates, for their encouragement and support. The rush of time and the lack of professional level of the whole paper certainly have not yet found the shortcomings and mistakes. I am very grateful to the teachers and students who point out the problems.

\section{REFERENCES}

[1] Ye tai Fei. Error Theory and Data Processing. China Machine PRESS, 2000year, p. 83-92.

[2] Zhen liang Ding. Error Theory and Data Processing. Harbin Institute of Technology Press, 2002year, p. 102-115.

[3] Information on:

http://baike.baidu.com/link?url=0Ulv6FIBXDnsyIgUQENM OWrBnNHQdhqiArA6SqBNhWthzMBCoIeVnJh-tKCsq2gr14aWr54DwihCO-hw62_4a

[4] Information on: http://wenku.baidu.com/link?url=_2jkSP6YlAi72HIRVY2iw bGH_lsCvXdHc6iqo_a4Nzph_ubZ2DwqsCTjHdysK_QRXJ F4Qkp1g8scvzgKeOLmOBvKSQ6NmDzVkWLnmgBl9TG 